\title{
Avalanche risk assessment - a multi-temporal approach, results from Galtür, Austria
}

\author{
M. Keiler ${ }^{1}$, R. Sailer ${ }^{2}$, P. Jörg ${ }^{2}$, C. Weber ${ }^{3}$, S. Fuchs ${ }^{4}$, A. Zischg ${ }^{5}$, and S. Sauermoser ${ }^{6}$ \\ ${ }^{1}$ Department of Geography and Regional Research, University of Vienna, Austria \\ ${ }^{2}$ Federal Research and Training Centre for Forests, Natural Hazards and Landscape (BFW), Department of Natural Hazards \\ and Alpine Timberline, Innsbruck, Austria \\ ${ }^{3}$ Federal Service for Torrent, Erosion and Avalanche Control, District Office Imst and Landeck, Austria \\ ${ }^{4}$ Institute of Mountain Risk Engineering, University of Natural Resources and Applied Life Sciences, Vienna, Austria \\ ${ }^{5}$ Geo Information Management, Gargazzone, Italy \\ ${ }^{6}$ Federal Service for Torrent, Erosion and Avalanche Control, Section Tyrol, Innsbruck, Austria
}

Received: 1 August 2005 - Revised: 10 May 2006 - Accepted: 10 May 2006 - Published: 19 July 2006

\begin{abstract}
Snow avalanches pose a threat to settlements and infrastructure in alpine environments. Due to the catastrophic events in recent years, the public is more aware of this phenomenon. Alpine settlements have always been confronted with natural hazards, but changes in land use and in dealing with avalanche hazards lead to an altering perception of this threat. In this study, a multi-temporal risk assessment is presented for three avalanche tracks in the municipality of Galtür, Austria. Changes in avalanche risk as well as changes in the risk-influencing factors (process behaviour, values at risk (buildings) and vulnerability) between 1950 and 2000 are quantified. An additional focus is put on the interconnection between these factors and their influence on the resulting risk.

The avalanche processes were calculated using different simulation models (SAMOS as well as ELBA+). For each avalanche track, different scenarios were calculated according to the development of mitigation measures. The focus of the study was on a multi-temporal risk assessment; consequently the used models could be replaced with other snow avalanche models providing the same functionalities. The monetary values of buildings were estimated using the volume of the buildings and average prices per cubic meter. The changing size of the buildings over time was inferred from construction plans. The vulnerability of the buildings is understood as a degree of loss to a given element within the area affected by natural hazards. A vulnerability function for different construction types of buildings that depends on avalanche pressure was used to assess the degree of loss. No general risk trend could be determined for the studied avalanche tracks. Due to the high complexity of the vari-
\end{abstract}

Correspondence to: $\mathrm{M}$. Keiler

(margreth.keiler@univie.ac.at) ations in risk, small changes of one of several influencing factors can cause considerable differences in the resulting risk. This multi-temporal approach leads to better understanding of the today's risk by identifying the main changes and the underlying processes. Furthermore, this knowledge can be implemented in strategies for sustainable development in Alpine settlements.

\section{Introduction}

Avalanches are natural processes in alpine regions. The exposure of people and properties as well as infrastructure renders these natural processes hazardous. In the Alps, strategies to avert or to reduce the effects of natural hazards in areas of settlements and economic activities have a long tradition. In the second half of the nineteenth century, official authorities were founded in Switzerland (Frutiger, 1980) and in Austria (e.g. in the year 1884) (Bergthaler, 1975) to organise protection against natural hazards. In the following half century, permanent measures reducing and deflecting hazard processes were developed and built. High investments were required for 'reactive' mitigation measures after extreme avalanche events and debris flow events in the 1950s and 1960s. Due to limited financial resources, it was not feasible to build such structures in all endangered areas. This situation changed the way in which natural hazards are dealt with, and additional "passive" mitigation measures, e.g. hazard zone maps, were introduced. To identify hazard zones, defined design events are used in order to estimate the range and pressure distribution of the processes (Weiss, 2002). In spite of the successful application of the hazard zone maps since the mid-1970s, natural hazards caused large damage in

Published by Copernicus GmbH on behalf of the European Geosciences Union. 
settlement areas in the 1990s, as shown for Switzerland by Bründl and Hegg (2001), and particularly due to avalanches in the winter 1999 in the whole Alpine region (Heumader, 2000; SLF, 2000). The increased use of hazard-prone areas for human settlement and related infrastructure has been assumed to be responsible for the increased losses during periods of high hazard activity (see e.g. Ammann, 2001; Barbolini et al., 2002). This trend - recognised world-wide induced White, Kates and Burton (2001) to publish a review of books addressing natural hazard research, with the title "Knowing better and losing even more - the use of knowledge in hazard management". One of their proposed explanations for this observed increase includes a rise in vulnerability and in population, in wealth and in poverty (White et al., 2001). Additionally, the authors point out that comprehensive data is lacking on recorded and estimated losses in proportion of the total monetary values.

The rising losses led to an increased emergence of the risk concepts in natural hazard research since the 1990s. In the area of natural science, risk $\left(R_{i, j}\right)$ dependent on scenario $i$ and object $j$ is defined as a function of the probability of scenario $i\left(p_{S i}\right)$, the value of object $j\left(A_{O j}\right)$, the probability of exposure of object $j$ to scenario $i\left(p_{O j, S i}\right)$ and the vulnerability of object $j$, dependent on scenario $i\left(v_{O j, S i}\right)$, see Eq. (1):

$R_{i, j}=p_{S i} \cdot A_{O j} \cdot p_{O j, S i} \cdot v_{O j, S i}$

A fundamental characteristic of risk resulting from natural hazards is the connectivity between the physical system (or geosystem, governing the physical part of the process) and the social system (including values at risk and vulnerability). Both systems are subject to continuous changes over time. Caused by these dynamics, new interaction emerges and therefore enhanced connectivity can develop. Increasing connectivity is likely to induce higher complexity (Hufschmidt et al., 2005). Hence, rising losses related to natural hazard processes can neither be solely connected to the changes of the natural processes nor to the development of the damage potential and the vulnerability. These losses are the result of increasing complexity.

In Alpine countries, the emphasis in natural hazard research has so far been on the determination of the hazard potential and the related probability of occurrence by examining, modelling, and assessing individual processes. Only recently, attention has been given to damage potential (Keiler et al., 2004; Kleist et al., 2004; BWG, 2005; Fuchs et al., 2005; Zischg et al., 2005) and the vulnerability as well as to the connectivity of these factors used for the risk assessment. Furthermore, risk analyses applied to natural hazards are in general static approaches (Jónasson et al., 1999; Keylock et al., 1999; Gächter and Bart, 2002; Bell and Glade, 2004). However, risk related to natural hazards is subject to temporal changes since the risk-influencing factors are variable over time (Fuchs and Keiler, 2006).
In the twentieth century, the natural avalanche activity seems to be neither significantly increasing nor decreasing, although the variability of events makes an exact statement difficult (Bader and Kunz, 1998; Schneebeli et al., 1998; Laternser, 2002). Thus, it can be assumed that changes of the natural processes are due to the construction of permanent mitigation measures in the release areas or run out areas of avalanche tracks. In Switzerland, about EUR 1 billion has been invested for this purpose since 1950 (SLF, 2000).

The societies in the Alps have undergone considerable socio-economic changes since the mid-twentieth century. This development reflects a shift from farming-based activities towards a tourism and leisure-time-orientated economy (Bätzing, 1993). Contemporaneously, settlements and the population increased significantly in the Eastern Alps. A similar trend is outlined for the damage potential in Keiler (2004); Fuchs and Bründl (2005); Keiler et al. (2005).

The factor vulnerability is crucial for a coherent risk assessment. However, large gaps in the knowledge about vulnerability exist, as well as different ways of understanding vulnerability. Cutter (1996) listed 18 definitions of vulnerability to environmental hazards, which arose between 1980 and 1995. She states that many of the discrepancies in the meanings of vulnerability develop from different epistemological orientations (physical science, political ecology, human ecology, spatial analysis). In natural science vulnerability is related to the susceptibility of people, buildings and infrastructure with respect to the hazard. The consequences are expressed as the degree of loss and the results are the probability of lives or monetary values lost (IUGS, 1997). In social science vulnerability can be understood as "the characteristics of a person or group and their situation that influence their capacity to anticipate, cope with, resist and recover from, the impact of a natural hazard" (Wisner et al., 2003: 11). There is a lack of studies on vulnerability related to avalanches in general as well as on temporal changes of vulnerability in both natural science and social science.

The objective of this study was to partly close this gap by studying temporal changes of avalanche risk. To assess the avalanche risk based on a temporal approach, riskinfluencing factors have to be analysed over time. Changes of the risk-influencing factors have natural, social, economical and technical reasons. Therefore, the development of those factors has to be regarded separately and their interconnections have to be analysed. In this study, the avalanche risk is calculated for the number and the value of endangered buildings using Eq. (1) in steps of decades from 1950 to 2000 to illustrate dynamic changes. Thus, the probability of exposure of object $j$ to scenario $i\left(p_{O j, S i}\right)$ was given the value of one since buildings are immobile property. These risk analyses are carried out on three avalanche tracks in the commune of Galtür. The settlement of Galtür is highly endangered by avalanches, a fact that has been publicly known since the avalanche event of 1999 (Heumader, 2000; SLF, 2000). The study area Galtür is located in the inner Paznaun 
valley in Tyrol, Austria. The community is endangered by 26 avalanche tracks; 111 buildings with a value of EUR 64 million (year 2000) are located in the run out zone of these avalanches. Due to passive (e.g. hazard zone map) mitigation measures, the increase of buildings in the avalanche-prone area could be reduced. Thus, in combination with active mitigation measures (supporting structures, deflecting dam), nearly $75 \%$ of the buildings were protected (Keiler, 2004). Recent findings on occurring avalanche impact pressures $(p)$ after the avalanche event in 1999 led to changed pressure limits for the red $(p>10 \mathrm{kPa})$ and the yellow hazard zones $(1 \mathrm{kPa}<p<10 \mathrm{kPa})$ in Austria ${ }^{1}$. Hence, the red as well as the yellow hazard zones will be extended in the course of the revision of the legally binding hazard zone map during the next years. When delimiting the new hazard zones for avalanche tracks, traditional methods such as field studies and analyses of former avalanche events are used as well as simulation models. Therefore, the results of this study might also provide a basis for the implementation of the changed delimitation criteria and for the construction codes considering the vulnerability of the buildings.

\section{Method}

In the following sections the applied methods used for recording and analysing the changes of risk-influencing factors are described. The calculation of the avalanche risk is based on the probability of occurrence of the legally defined design event of 150 years. Therefore, the avalanche risk is expressed as the potential monetary loss of building values resulting from this design event.

\subsection{Avalanche processes and modelling}

In this study, two different avalanche simulation models were applied aiming for an enhanced plausibility of the results. The models SAMOS (version SAMOS99) as well as ELBA+ were developed in Austria under the auspices of the Austrian Ministry for Agriculture during the late 1990s. Both models are in operational use by the Federal Service for Torrent, Erosion and Avalanche Control. A detailed description for the model SAMOS is given by Sailer et al. (2002) and Sampl and Zwinger (2004). ELBA+ is an improved version of the model ELBA, which is described in-depth by Volk and Kleemayr (1999). The focus of the study was on a multitemporal risk assessment, thus the used models could be replaced with other snow avalanche models providing the same functionalities.

\footnotetext{
${ }^{1}$ BMLF (Austrian Federal Ministry of Agriculture and Forestry): Gefahrenzonenplanung, Richtlinien für die Abgrenzung von Gefahrenzonen, Übermittlung zur Anwendung, Bundesministerium für Land- und Forstwirtschaft, Abteilung V Forstwesen, Geschäftssache 52.240/10-VC6a/99, Wien, unpublished, 1999.
}

Table 1. Input parameters used for the simulation models SAMOS and ELBA+.

\begin{tabular}{lrr}
\hline Input parameter & ELBA+ & SAMOS \\
\hline Release density & $150 \mathrm{~kg} / \mathrm{m}^{3}$ & $150 \mathrm{~kg} / \mathrm{m}^{3}$ \\
Flow density & $200 \mathrm{~kg} / \mathrm{m}^{3}$ & $200 \mathrm{~kg} / \mathrm{m}^{3}$ \\
DEM cell size & $5 \mathrm{~m}$ & $5 \mathrm{~m}$ \\
Particle size (powder part) & - & $1 \mathrm{~mm}$ \\
Entrainment & No & No \\
Entrainment density & - & - \\
Critical normal stress & - & - \\
\hline
\end{tabular}

The flow part of the avalanches has been calculated with SAMOS and ELBA+. The associated powder part is a result of calculations with SAMOS. The input parameters were chosen for the design event with a reoccurrence interval of 150 years. Since the local records of avalanche events do not cover a 150 -year event, the extrapolated 150 -year amount of new snow in three days was taken instead, in accordance with international practice. The 150 -year event was applied because it serves as basis for the delimitation of the hazard zones in Austria. The values used during calculations are summarised in Table 1. For each avalanche track, the simulations were carried out first without any supporting structures in the release area (maximum scenario) and second under consideration of the existing mitigation measures (minimum scenario). For the minimum scenario it was assumed that the existing catching dam and the support structures are fully effective.

The settlement area in the study area is endangered by three main south-facing avalanches - Grosstal West, Grosstal East, Gidisrinner (cf. Fig. 1). Each of these avalanches was divided into several sub-release areas, concerning variable snow cover distributions and different protection measures (catching dam, support structures). Grosstal West shows the most differentiated release area and consists of seven subrelease zones at most (maximum scenario) with a total area of $96000 \mathrm{~m}^{2}$ (33 kt release mass). Approximately one third of this area has been covered with supporting structures since 1977. As the Grosstal West avalanche is not directly connected to the main mountain ridge the used snow depths (1.5 $\mathrm{m}$ to $2.25 \mathrm{~m}$ ) for the simulation are slightly lower compared to the other two avalanches. In contrast, the Grosstal East avalanche starts directly beneath the main ridge and is divided only in two release areas $\left(78000 \mathrm{~m}^{2}, 26.4 \mathrm{kt}\right.$ release mass). At the lower border of the cirque a catching dam was built by the Federal Service for Torrent, Erosion and Avalanche Control in 1982. The front of this dam itself acts as a small release area; according to the simulations, it may be neglected in this context. The release zone of the third avalanche track - the Gidisrinner avalanche - differs again from the two others; this release area shows a large vertical 


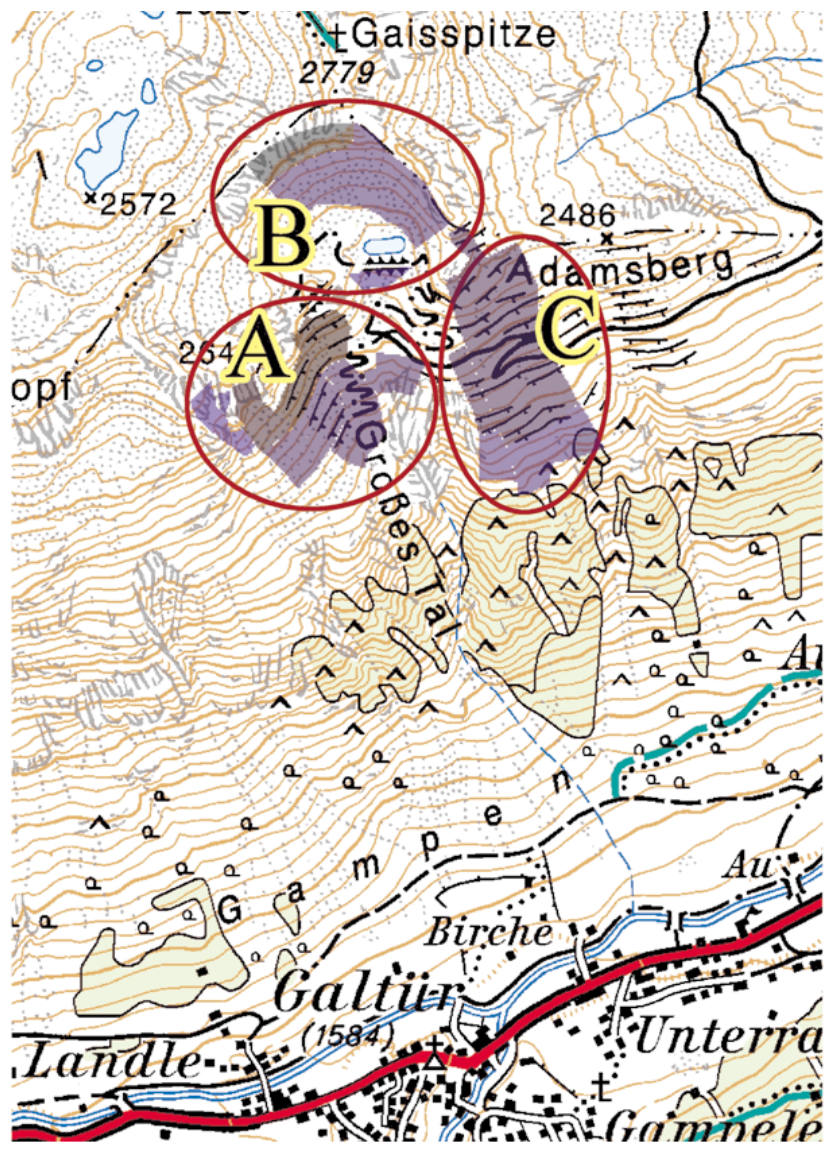

Fig. 1. Avalanche sites and release areas (Grosstal West avalanche (A), Grosstal East avalanche (B), Gidisrinner avalanche (C)) in the study area of the community Galtür. Areas of the release area coloured in light blue indicate small release depths $(>1.0 \mathrm{~m})$ and areas coloured in grey indicate large release depths $(<2.4 \mathrm{~m})$. Map basis reproduced with permission of Bundesamt für Eich- und Vermessungswesen, Blatt 170, Galtür.

range. The major part $(80 \%)$ of the release zone has been covered with support structures since 1989. The remaining $20 \%$ are the lowermost region with a release depth in the order of 1.3 and $1.75 \mathrm{~m}$ due to the large distance to the mountain ridge. The Gidisrinner avalanche is subdivided into three release areas with a total area of $135000 \mathrm{~m}^{2}$ and a release mass of at most $40 \mathrm{kt}$. The aggregated release areas and mass of each avalanche is shown in Table 2 for the minimum as well as for the maximum scenario of the simulation.

The simulations with SAMOS provide information on velocity, deposit distribution, deposit depth and impact pressure of each avalanche. For this study, the impact pressure of the avalanche on buildings was the most important factor. The following statements on peak pressures apply to the lowest layer of the three-dimensional grid used for simulating the powder-snow part at approximately $2.5 \mathrm{~m}$ above the dense-flow part. The impact pressure at affected buildings
Table 2. Aggregated release areas and release masses of the three avalanche tracks for the maximum and the minimum scenario.

\begin{tabular}{lrrrr}
\hline \multirow{2}{*}{ Avalanche } & \multicolumn{2}{c}{ Release mass [kt] } & \multicolumn{2}{c}{ Release area $\left[\mathrm{m}^{2}\right]$} \\
& minimum & maximum & minimum & maximum \\
\hline Grosstal West & 19.0 & 33.0 & 59000 & 96000 \\
Grosstal East & 26.4 & 26.4 & 78000 & 78000 \\
Gidisrinner & 8.1 & 39.9 & 33000 & 135000 \\
\hline
\end{tabular}

was taken to be the pressure at the respective polygon centre for the further vulnerability analysis.

\subsection{Building values at risk}

The monetary values of buildings were calculated using the volume of the buildings and average prices per cubic meter for new buildings, as used by insurance companies. The recent size of the buildings was recorded from digital datasets of the communality administration and provided the basis for the evaluation of the values. The changing size of the buildings in the course of time was inferred from construction plans or construction descriptions. Thus, the original building size could be traced back to the year 1950. For the value calculation different price levels were applied, depending on the function of the buildings as well as on the number and kind of storeys. This information was mapped in the field or extracted from the construction descriptions. The evaluation was carried separately for each decade using the 2002 price level. In order to allow intersection with the avalanche process data for the further analysis, digital information on the location of the buildings was provided by the government of the State of Tyrol, Division of Spatial Planning and Statistics (TIRIS). The digital data was incorporated in a Geographical Information System (GIS) and updated by fieldwork and interpretation of orthophotos. Additionally, the values and the functions of the buildings as well as their year of construction were joined to the spatial data in the GIS (Keiler, 2004).

\subsection{Vulnerability}

In natural hazard risk assessment, the vulnerability factor is used in different contexts. The term vulnerability is restricted in the perception of natural and technical science as the degree of loss $(0=$ no loss, $1=$ total loss $)$ to a given element or set of elements within the area affected by natural hazards (for a compilation, see Glade, 2003). However, standardised approaches to evaluate the effects of avalanches to buildings are still missing (Hollenstein et al., 2002). Barbolini et al. (2004) proposed an empirical vulnerability relation for alpine buildings based on the studies of Jónasson et al. (1999) and Keylock and Barbolini (2001). To this end, two avalanche events in Austria were re-calculated with the model SAMOS, and the impact pressure of the avalanches 
was estimated for each affected building. Knowing the degree of damage and the deduced specific loss of the buildings, the vulnerability function was analysed for five impact pressure ranges (Barbolini et al., 2004). However, the heterogeneous construction methods of buildings in the Alps due to their age and function as well as socio-economic changes are disregarded in the estimation of Barbolini et al. (2004). Especially for a temporal approach of avalanche risk assessment this perspective is very important in the vulnerability analysis. Therefore, the vulnerability functions for different construction types of buildings (building categories) related to avalanche pressure (expressed in $\mathrm{kPa}$ ) were used in this study, as outlined in Wilhelm (1997) (Fig. 2). The susceptibility of loss to the building categories is partly based on the analyses of destroyed buildings during the avalanche winter 1954 in Vorarlberg, Austria, by Voellmy (1955) (cf. Wilhelm 1997).

Wilhelm (1997) differentiates between four vulnerability thresholds (see Fig. 2):

- The general damage level $\left(p_{u}\right)$ corresponds to an avalanche pressure of $2-3 \mathrm{kPa}$ and causes mentionable damage (estimated at $3 \%$ ), such as destroyed windows and doors.

- The specific damage level $\left(p_{u i}\right)$ is the consequence of an avalanche impact pressure that inflicts damage on the building structure. Thus, each building category has a different specific damage level due to its different construction type.

- The destruction level $\left(p_{o i}\right)$ describes the avalanche pressure that can produce maximum loss within each building category.

- The detach limit $\left(p_{a i}\right)$ of each building category describes a damage threshold below the destruction level, but demolition and reconstruction of the buildings is necessary. Therefore, maximum loss is postulated for a degree of susceptibility to loss of 50\% and more because additional costs arise for the demolition and reconstruction that can add up to the maximum loss.

For the vulnerability assessment, the existing buildings were categorised by mapping in the field. Additionally, the date of construction, the construction plans and descriptions as well as the functions of the buildings were used to identify the building categories back to the 1950s. The vulnerability of buildings can be remarkably reduced by integrated mitigation measures, like avalanche deflectors and reinforced construction on the exposed side of the buildings (Fig. 3). In the study area, avalanche deflectors have a long tradition as protecting measures and can be traced back to the year 1613 (Gemeinde Galtür, 2006). Therefore, avalanche deflectors were identified in the field and their effectiveness was assessed. Since the introduction of the legally binding hazard zone maps in 1986, buildings in the red and in the yellow hazard zone have

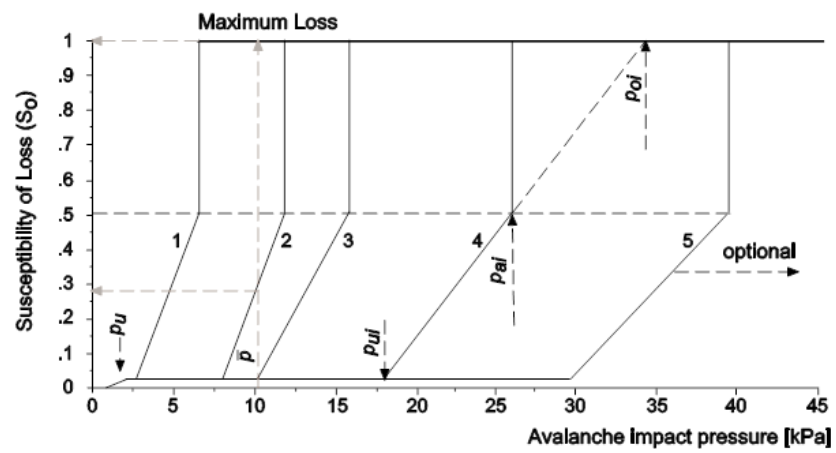

Fig. 2. The degree of possible loss is a function of the avalanche impact pressure and the vulnerability of buildings, the latter varies due to the material used for construction (building categories). Building categories: $1=$ lightweight construction, $2=$ mixed construction, $3=$ massive construction, $4=$ concrete reinforced construction, $5=$ reinforced construction. Limiting values: $p_{u}=$ damage level, $p_{u i}=$ specific damage level, $p_{a i}=$ detach limit, $p_{o i}=$ destruction level, $p=$ avalanche pressure (outlined in Wilhelm, 1997: 72).

to fulfil special construction requirements to reduce possible damage. These requirements are defined for each existing building as well as for new buildings due to the specific hazard (avalanche pressure) by the Federal Service for Torrent, Erosion and Avalanche Control and are documented in the construction records of the commune. For the study it was assumed that these special requirements were implemented accordingly. Hence, they have been considered in the vulnerability assessment. These construction requirements have only become operative in the legally binding hazard zones. However, the results of the simulated run-out zones might not always be congruent with these hazard zones. Thus, buildings outside the hazard zone can be exposed to the simulated avalanche pressures, but no special construction regulations exist for these buildings. Due to the different vulnerability caused by this aspect, the proportion of buildings inside to buildings outside the hazard zones is calculated to get further information on losses.

\section{Results}

In the following sections, an overview of the general results for each factor of the risk equation (Eq. 1) associated with the temporal avalanche risk assessment is given. Changes of the avalanche risk related to the three avalanche tracks are shown in detail.

3.1 Changes in the avalanche run out zone and in the avalanche pressure

The flow part of the avalanches, calculated with SAMOS and ELBA+ reaches the valley floor neither in the minimum nor in the maximum scenario. For the maximum scenario 


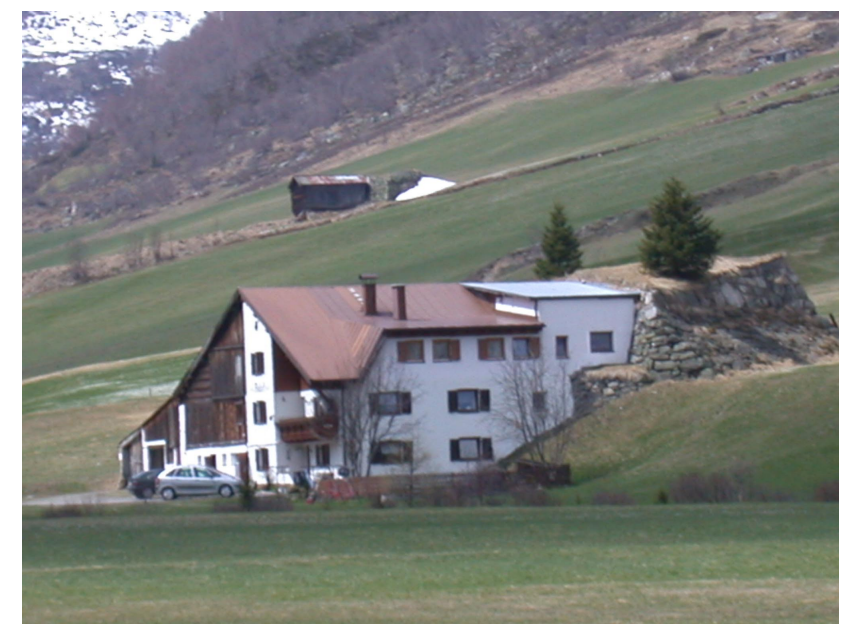

Fig. 3. Building with an integrated avalanche deflector on the uphill side of a building located in the community of Galtür.

of the Grosstal West avalanche track, only two very exposed buildings are marginally affected by the simulated flow part. However, the minimum and maximum scenarios of each avalanche differ significantly. The minimum scenarios predict short run-out lengths whereas no considerable differences between SAMOS and ELBA+ are observable. Solely the lateral spread of the flow part calculated with SAMOS is slightly wider than that of ELBA+ simulations. This is a well known phenomenon with no effect on buildings or forests in this particular case. This malfunction is already improved in the advanced version of SAMOS (version SAMOS04), which is under development.

Due to the steep terrain, the variance of the powder part is less distinctive between minimum and maximum scenario. The reduced mass of the minimum scenario seems to be large enough to supply the powder part with sufficient snow. After the hold-up of the flow part, the powder part overflows the bottom of the unobstructed valley. In general, the peak pressures obtained from SAMOS simulations are relatively low for the calculated avalanches in the study area. For the maximum scenario, the highest impact pressure on a building was calculated at $23 \mathrm{kPa}$. Eight percent of the buildings are exposed to pressures above $10 \mathrm{kPa}$ and nearly $28 \%$ to an impact above $5 \mathrm{kPa}$. Regarding the minimum scenario, the highest pressure amounts to $13 \mathrm{kPa}$ and only three percent of the buildings are exposed to an impact above $10 \mathrm{kPa}$. The proportion of the number of buildings endangered by a pressure above $5 \mathrm{kPa}$ was reduced to $13 \%$. The $30 \mathrm{kPa}$ outline does not touch the settlement area. The peak pressures of the powder part on other buildings in the investigation area are below this value. The results of the SAMOS model (powder part) of the Gidisrinner avalanche are illustrated in Fig. 4.

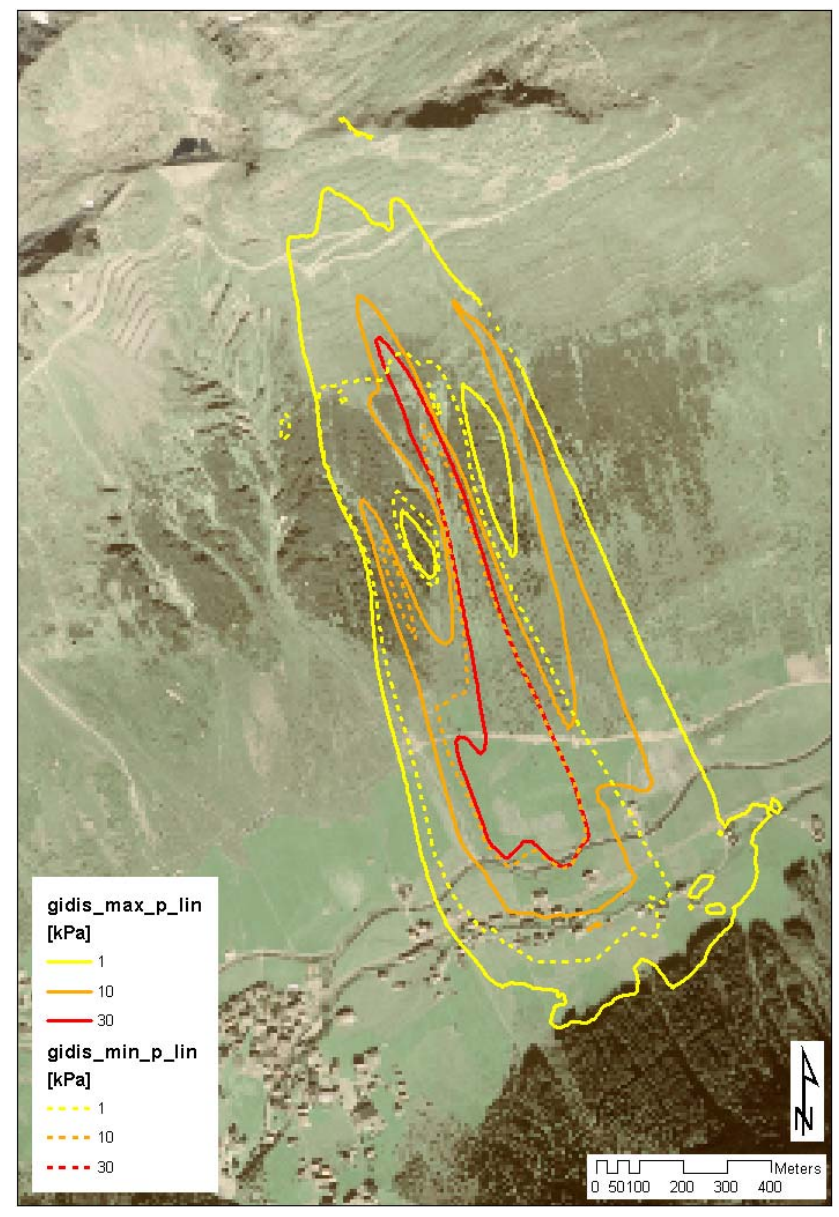

Fig. 4. Comparison of the extent of the avalanche run-out zone of the Gidisrinner avalanche, calculated for the minimum (dashed lines) and maximum (solid lines) scenarios using the simulation model SAMOS to model the flow and powder part of the avalanche.

\subsection{Changes of building values at risk}

In the study area, the total building values (corresponding to the maximum scenario) rose by a factor of five between 1950 and 2000. This increase of values is below the development of the total value of all buildings in the community (factor of 8 , Keiler, 2004). A similar trend is found for the number of buildings, however with a smaller difference (factor of 2.4 for the study area and a factor of 2.6 for the entire commune). The stronger increase of the building values compared to the number of buildings is due to changes in the function of the buildings from farm buildings or basic residential buildings to buildings with tourist infrastructure like guest houses or hotels. Additional factors are the rising building sizes as a result of the reconstruction of buildings and/or the extension of existing building (Keiler, 2004). 


\subsection{Changes of vulnerability}

The vulnerability of the buildings in the study area was subject to temporal changes. In general, buildings were shifted from category 2 to category 3 due to a) changes in the building functions and b) associated changes of structure and of construction materials (see Fig. 2).

To determine a general development of the vulnerability factor, the total building values were compared to the calculated possible loss considering the susceptibility of the buildings to the avalanche pressure. In 1950, an average loss of $7 \%$ of the total building values was estimated for all avalanche tracks if a design event had occurred.

In 2000, this proportion was continuously reduced to about $3.5 \%$ for the Grosstal West avalanche and to about $2.8 \%$ for the Grosstal East avalanche due to changes in the building categories (Table 3 and Fig. 2).

For the area affected by the Gidisrinner avalanche, the development of the vulnerability was influenced by the construction of buildings in areas where high peak pressures of the powder part occur. Therefore, the proportion of possible losses to the total building values increased to $26.6 \%$ until 1980. The introduction of the construction requirements in the 1980s caused a change from the building category 4 to the building category 5 . Thus, the proportion of the possible losses compared to the total building values exposed to the Gidisrinner avalanche was reduced to $6 \%$ in 2000 .

\subsection{Development of avalanche risk}

The following results show the changes of the avalanche risk, expressed as the potential monetary loss of buildings resulting from the occurrence of the defined design event. First, the development of the number of buildings exposed to the different impact pressures due to the calculation of the maximum and the minimum extent of the different avalanche runout zones is given. Furthermore, for each avalanche track different risk scenarios were calculated in steps of decades between 1950 and 2000:

- Risk scenario A describes the development of the total building values at risk in the maximum extent of the avalanche. Accordingly, the influence of mitigation measures and the vulnerability of the elements at risk were not considered (the factor vulnerability is set to one). This scenario corresponds to the term "possible maximum loss" (PML, total damage) in the insurance industry.

- Risk scenario B shows the cumulative possible loss regarding the maximum extent of the avalanche if no mitigation measures had been constructed. The vulnerability of the elements at risk was taken into account.

- Risk scenario C illustrates the real-time change of the possible loss, taking into account changes of all three
Table 3. Number of exposed buildings regarding the maximum scenario of all three avalanches divided in the different building categories cf. Wilhelm (1997) and their proportion to the total number of exposed buildings in the year 1950 and 2000. Building categories: 1 = lightweight construction, $2=$ mixed construction, $3=$ massive construction, $4=$ concrete reinforced construction, $5=$ reinforced construction.

\begin{tabular}{rrrrr}
\hline Building categories & $\begin{array}{r}1950 \\
\text { Number of } \\
\text { buildings }\end{array}$ & $\%$ & $\begin{array}{r}2000 \\
\text { Number of } \\
\text { buildings }\end{array}$ & $\%$ \\
\hline 1 & 5 & 14 & 5 & 6 \\
2 & 17 & 48 & 24 & 29 \\
3 & 10 & 29 & 33 & 40 \\
4 & 0 & 0 & 9 & 11 \\
5 & 3 & 9 & 12 & 14 \\
Total & 35 & 100 & 83 & 100 \\
\hline
\end{tabular}

risk-influencing factors, (1) the shifts in the values at risk, (2) the varying vulnerability of buildings and (3) the construction of supporting structures.

\subsubsection{Number of buildings}

\section{Grosstal West avalanche}

In the study area, the highest number of buildings has been located in the run-out zone of the Grosstal West avalanche (maximum scenario) since the 1950s (Fig. 5). Furthermore, in this area, the strongest increase in the number of buildings between 1950 and 2000 was calculated (by a factor of 2.5, Fig. 6). Considering the reduction of the run-out zone due to supporting structures (minimum scenario), this factor was 2.3 in the year 2000 (Fig. 6). The construction of avalanche supporting structures in the release area in 1977 showed nearly no effect on the simulated impact pressure and the extent of the run-out zone. However, only five of 42 buildings were exposed to an impact pressure higher than $5 \mathrm{kPa}$ in the year 2000 , according to the maximum scenario (Table 4). In 2000, 39 buildings were located in the run-out zone of the minimum scenario (Fig. 5a) and still five buildings were exposed to an impact pressure higher as $5 \mathrm{kPa}$ (Table 4). Concerning the simulation results, most of the buildings endangered by the Grosstal West avalanche were situated outside the legally declared avalanche-prone area (Fig. 5a). The proportion of buildings located inside a hazard zone (red or yellow) compared to the exposed buildings outside the hazard zones provided information on a) the influence of hazard zone map on the land use planning as well as b) on the amount of buildings inside the hazard zone which were affected by the construction requirements. This proportion increased continuously from 
Table 4. Number of buildings exposed to different impact categories (in $\mathrm{kPa}$ ) in the run-out zones of the avalanche tracks in the year 1950 and 2000 , considering both maximum scenario (= max, without supporting structure in the release area) and minimum scenario (= min, with supporting structure in the release area).

\begin{tabular}{lcrrrrrrrrrrr}
\hline \multirow{2}{*}{ Avalanche } & \multicolumn{1}{c}{ Year } & \multicolumn{2}{c}{$<5$} & \multicolumn{3}{c}{$5-<10$} & \multicolumn{2}{c}{$10-<15$} & \multicolumn{2}{c}{$15-<20$} & \multicolumn{2}{c}{$20-<25$} \\
& & $\max$ & $\min$ & $\max$ & $\min$ & $\max$ & $\min$ & $\max$ & $\min$ & $\max$ & $\min$ \\
\hline \multirow{3}{*}{ Grosstal West } & 1950 & 15 & - & 0 & - & 2 & - & 0 & - & 0 & - \\
& 2000 & 37 & 34 & 3 & 3 & 2 & 2 & 0 & 0 & 0 & 0 \\
Grosstal East & 1950 & 6 & - & 0 & - & 0 & - & 0 & - & 0 & - \\
\multirow{3}{*}{ Gidisrinner } & 2000 & 14 & 8 & 1 & 1 & 0 & 0 & 0 & 0 & 0 & 0 \\
& 1950 & 6 & - & 5 & - & 1 & - & 0 & - & 0 & - \\
& 2000 & 10 & 10 & 12 & 2 & 3 & 0 & 1 & 0 & 1 & 0 \\
\hline
\end{tabular}

Table 5. Average values (in EUR) per building between 1950 and 2000 for buildings located in the run out zone of the study area, considering the maximum scenario.

\begin{tabular}{lrrrrrr}
\hline \multirow{2}{*}{ Buildings located in the run out zones } & \multicolumn{6}{c}{ Average values (in EUR) per building } \\
& 1950 & 1960 & 1970 & 1980 & 1990 & 2000 \\
\hline Grosstal West avalanche & 395000 & 467000 & 676000 & 754000 & 780000 & 826000 \\
Grosstal East avalanche & 742000 & 776000 & 990000 & 1341000 & 1667000 & 1556000 \\
Gidisrinner avalanche & 256000 & 314000 & 321000 & 454000 & 410000 & 596000 \\
All avalanches & 464000 & 519000 & 662000 & 850000 & 983000 & 992000 \\
\hline
\end{tabular}

$24 \%$ in 1950 to $36 \%$ in 2000 (Fig. 5a). The buildings outside the hazard zone were exposed to lower impact pressures.

\section{Grosstal East avalanche}

In contrast to the Grosstal West avalanche, only six buildings were exposed to the Grosstal East avalanche in 1950 (Fig. 5b). In 2000, the number of buildings in this area increased to 14 buildings in the maximum scenario (i.e., by a factor of 2.3, Fig. 6) and to nine buildings for the minimum scenario (Fig. 5b; equals a factor of 1.5, Fig. 6), respectively. According to the simulations, an impact pressure of $5 \mathrm{kPa}$ occurred for one building both in the maximum and in the minimum scenario (Table 4). For all other buildings, the peak pressure of the powder part was below this value (Table 4). By 1970, the number of buildings in the simulated avalanche-prone area (maximum scenario) had doubled, whereas the proportion of buildings in the area of the legally binding hazard maps to buildings outside this area was 50\% in 1950 and decreased to $42 \%$ until 1970 (Fig. 5b). This change was caused by intensified development in the fringe area of the avalanche run-out zone. Between 1970 and 1980, the number of buildings did not change in the area of the maximum scenario. It declined by one third to eight buildings due to the construction of the catching dam in the release area in 1982 (Fig. 5b). Regarding the simulated run-out zone of the minimum scenario, this dam was more effective in protecting buildings in the hazard zones because in this area, the number of exposed buildings was more strongly reduced than outside the hazard zones. Therefore, the proportion of buildings inside the hazard zone to buildings outside the hazard zone was reduced to $22 \%$ (Fig. 5b), but for different reasons compared to the period between 1950 and 1970.

\section{Gidisrinner avalanche}

In 1950, twelve buildings were located in the simulated hazard-prone area of the Gidisrinner avalanche (maximum scenario, Fig. 5c). For the maximum scenario, this number increased to 27 buildings until 2000 (equals a factor of 2.3, Fig. 6). Regarding the minimum scenario after the construction of the supporting structures in the 1980s, the number of buildings in this avalanche-prone area was reduced from 20 to ten (Fig. 5c). Due to renewed construction activity during the 1990 s, an equal number of buildings was situated in the avalanche-prone area in 2000 (minimum scenario) as it had been in 1950 for the maximum scenario (Fig. 5c). The simulations showed the highest impact pressure in the study area to occur in this avalanche track (Table 4). One very exposed building, which was constructed in 1960, would be subjected to a pressure of $23 \mathrm{kPa}$ (Table 4). According to the maximum scenario in 2000, the peak pressure of the powder part exceeds $10 \mathrm{kPa}$ for five 

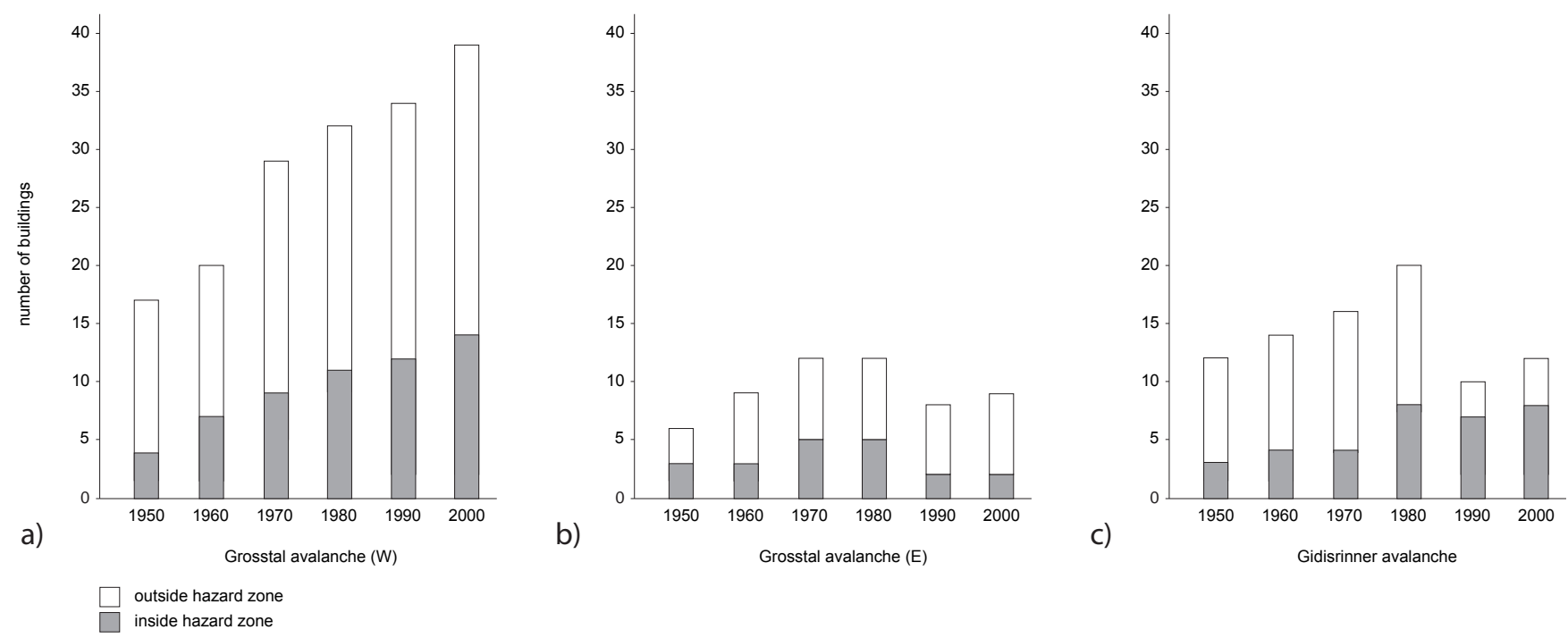

Fig. 5. Development of the number of buildings between 1950 and 2000 located in the run-out zones of the maximum scenario and after the construction of the mitigation measures (supporting structures, catching dam) in the run-out zones of the minimum scenario for the Grosstal West avalanche (a), the Grosstal East avalanche (b) and the Gidisrinner avalanche (c). The number of buildings is given separately for the buildings situated inside the legally binding hazard zones (introduced in the year 1986) and those situated outside the hazard zones.

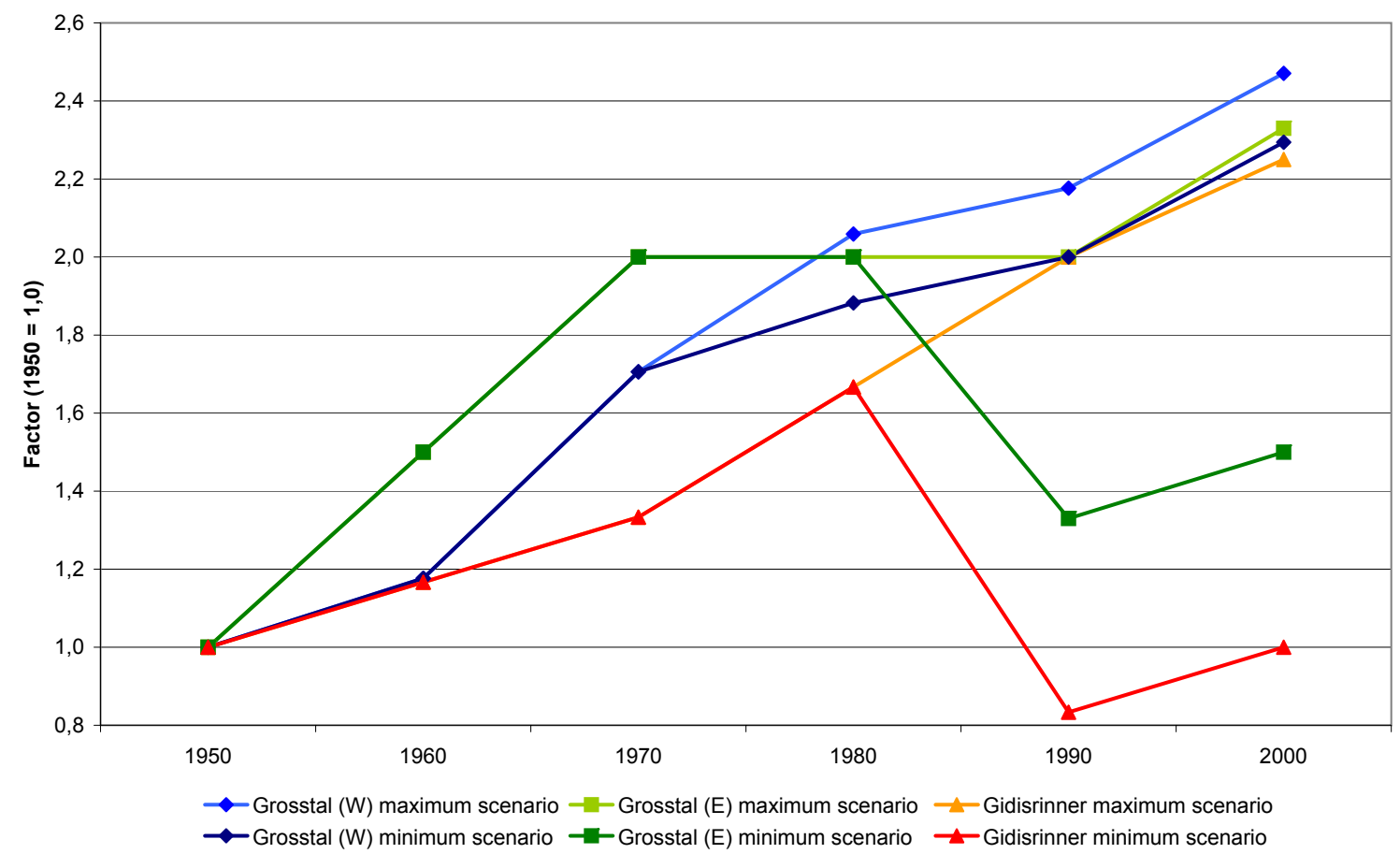

Fig. 6. Proportional development of the number of exposed buildings regarding the maximum scenario and the minimum scenario for all three avalanche tracks, 1950 as basis.

buildings and $5 \mathrm{kPa}$ for 17 buildings, respectively (Table 4). Due to the construction of supporting structures in 1989, the impact pressure on buildings was reduced to highest values of $7 \mathrm{kPa}$ (one building) and $5 \mathrm{kPa}$ (one building) (Table 4).
The proportion of buildings within the legal hazard zones to buildings outside hazard zones was almost a quarter until 1970 (Fig. 5c). During the 1970s, this proportion increased to $40 \%$ as a result of the construction of new buildings inside 


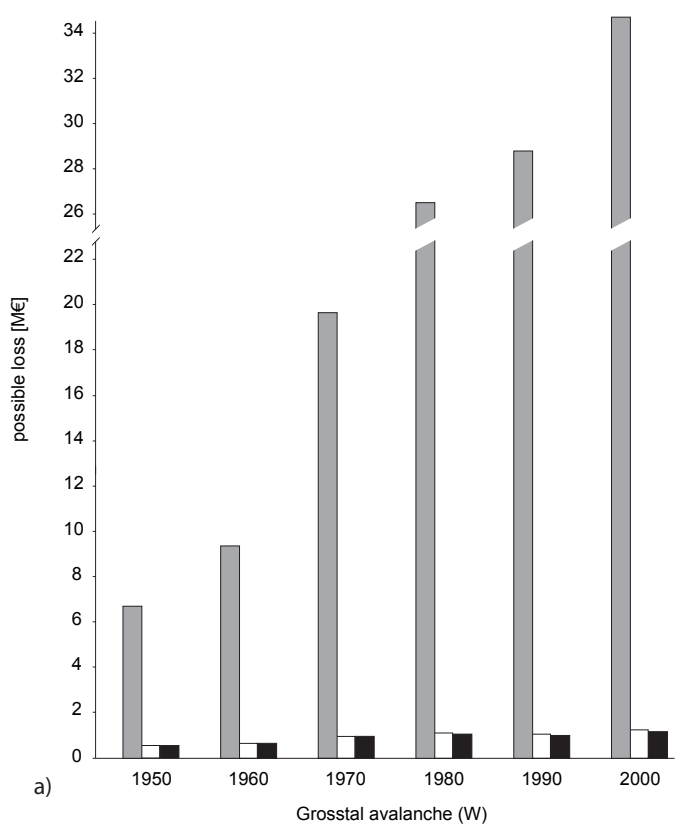

poss. loss without vulnerability (PML, risk scenario $A$ ) poss. loss including vulnerability (risk scenario B)
poss. loss including vulnerability and mitigation measures (risk scenario $\mathrm{C}$ )
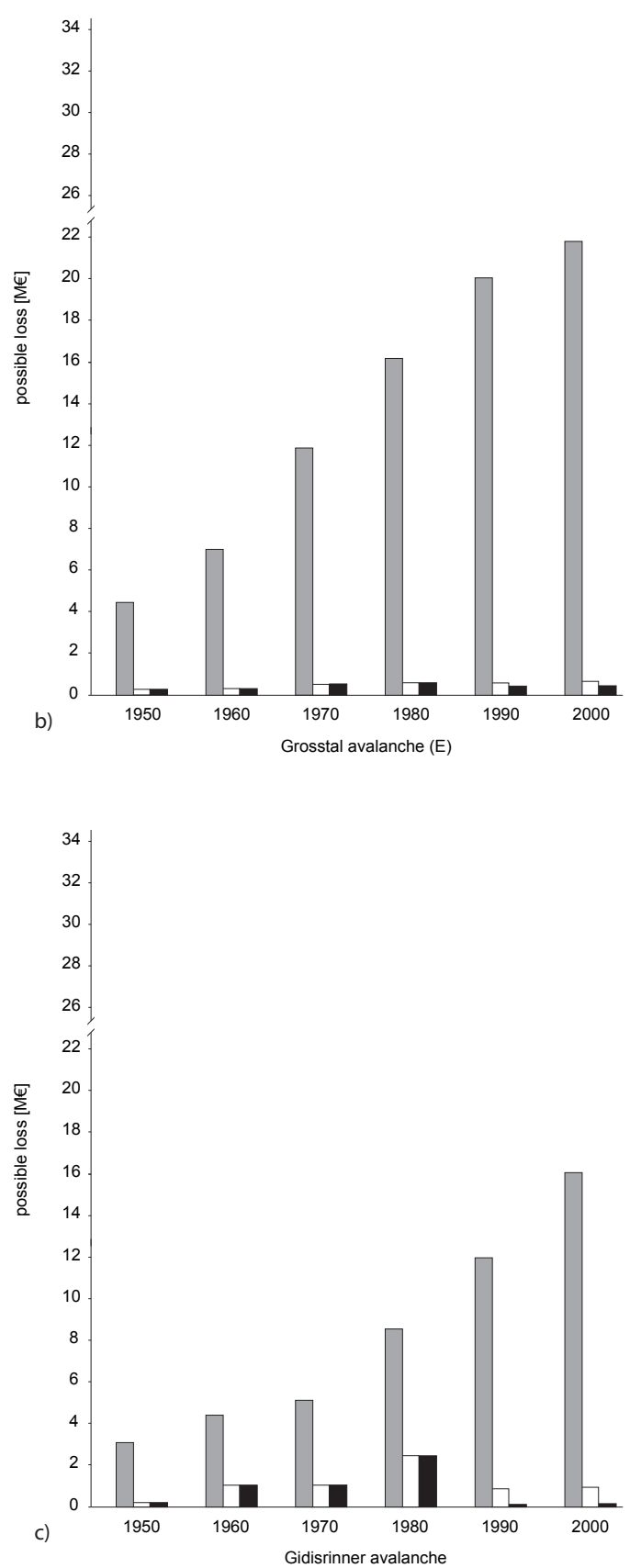

Fig. 7. Development of the possible losses related to the Grosstal West avalanche (a), the Grosstal East avalanche (b) and the Gidisrinner avalanche (c) regarding risk scenarios A, B and C between 1950 and 2000. Risk scenario A describes the development of the total building values at risk in the maximum extent of the avalanche. Risk scenario B shows the cumulative possible loss regarding the maximum extent of the avalanche if no mitigation measures had been constructed. The vulnerability of the elements at risk is taken into account. Risk scenario C illustrates the time change of the possible loss, taking into account changes of all three risk-influencing factors, (1) the shifts in the values at risk, (2) the varying vulnerability of buildings and (3) the construction of supporting structures.

the hazard zones (Fig. 5c). When supporting structures were built to reduce the avalanche-prone area, the proportion of buildings in the hazard zones to buildings outside the hazard zones rose further to $70 \%$ in 2000 (Fig. 5c).

\subsubsection{Risk scenario A}

According to the high number of buildings in the run-out zone of the Grosstal West avalanche, total building values 


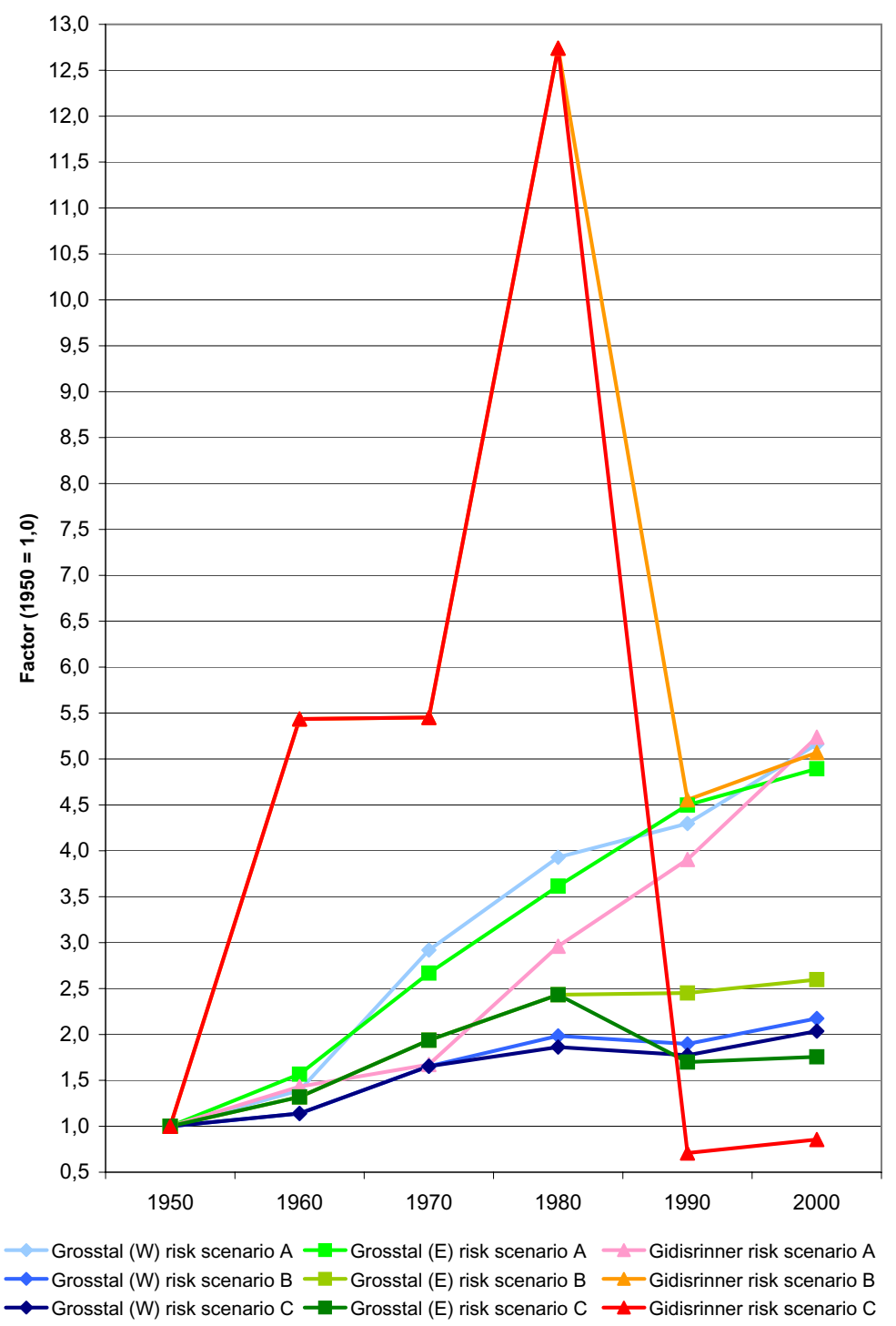

Fig. 8. Proportional development of risk scenarios A, B and C for the Grosstal West, the Grosstal East and the Gidisrinner avalanche, with the values of 1950 serving as basis. Risk scenario A describes the development of the total building values at risk in the maximum extent of the avalanche. Risk scenario B shows the cumulative possible loss regarding the maximum extent of the avalanche if no mitigation measures had been constructed. The vulnerability of the elements at risk is taken into account. Risk scenario C illustrates the time evolution of the possible loss, taking into account changes of all three risk-influencing factors, (1) the shifts in the values at risk, (2) the varying vulnerability of buildings and (3) the construction of supporting structures.

added up to already EUR 6.7 million in the endangered area in 1950 (Fig. 7a). The cumulative values increased to EUR 34.7 million in 2000 (Fig. 7a) (equals a factor of 5.2, Fig. 8) - by far the highest value for risk scenario A of all three avalanche tracks (Fig. 7). However, the corresponding average values per building in 2000 (EUR 826000 ) were below the mean values of the buildings of all three avalanche tracks (EUR 992000 in 2000, see Table 5).

The total building value at risk of the Grosstal East avalanche increased continuously between 1950 and 2000 from EUR 4.5 million to EUR 21.8 million (equals a fac- tor of 4.9, Figs. $7 \mathrm{~b}$ and 8 ), although there was no increase of the number of buildings between 1970 and 1990 for this scenario (Fig. 6). This trend was caused by the change of building functions as well as by the extension of buildings, as described in Sect. 3.2, and resulted in the highest average value per building in 2000 in the run out zone of the Grosstal East avalanche (EUR 1556000 ; Table 5).

The total building values in the Gidisrinner avalanche path showed a slighter increase until 1970 than those in the Grosstal avalanche paths (Fig. 8). However, until 2000, the values rose to EUR 16.1 million by the highest 
factor of 5.3 compared to 1950 (EUR 3.1 million, Fig. 7c). The total building values endangered by the Gidisrinner avalanche in the maximum scenario were very low compared to the Grosstal East avalanche (EUR 4.5 million in 1950, EUR 21.8 million in 2000, see Fig. 7b), where at almost any time only half as many buildings were located as in the run-out zone of the Gidisrinner avalanche. This considerable difference was caused by the different functions of the buildings; mainly large hotels and guest houses were endangered by the Grosstal East avalanche while mainly agricultural and residential buildings are threatened by the Gidisrinner avalanche. This was reflected in the lowest average value per building in 2000 (EUR 596000; Table 5).

\subsubsection{Risk scenario B}

The possible loss in the Grosstal West avalanche run-out zone according to risk scenario B, which considers the vulnerability of the buildings in the maximum scenario, showed a constant increase until the 1980s and a slight decrease after the introduction of the hazard zone map with special regulations for the building construction (Fig. 7a). Due to construction of new buildings, especially outside the official hazard zones, the possible losses according to risk scenario $\mathrm{B}$ increased again (Fig. 7a). In 2000, risk due to the Grosstal West avalanche had more than doubled compared to the values in 1950 (Fig. 8).

Risk scenario B for the Grosstal East avalanche showed a risk increase by a factor of 2.6 since the mid-20th century (Fig. 8). The introduction of the construction requirements in the hazard zones in 1986 has not resulted in a decline of the possible loss for this risk scenario as in the case of the Grosstal West avalanche (see Figs. 7a and b). However, the significant increase was slowed down. The effect of a reduction of the vulnerability due to the construction requirements could be explained by a) the low proportion of buildings inside the hazard zones to buildings outside the hazard zones and b) the above average increase of the values at risk in the years between 1970 and 1990 for the Grosstal East avalanche track.

The time evolution of risk in scenario B for the Gidisrinner avalanche is characterised by abrupt changes (Fig. 8). An increase by a factor of 5.4 between 1950 and 1960 was followed by a stable phase and a second increase with a doubling of the possible loss between 1970 and 1980 (equals a factor of 12.7 compared to 1950, Figs. 7c and 8). Due to the introduction of the construction requirements with the hazard zone map in 1986, the possible loss of risk scenario B in 1980 was reduced to nearly a third until 1990 (Fig. 7c). Therefore, the possible loss in risk scenario B for the Gidisrinner avalanche rose by a factor of 5.1 between 1950 and 2000 (Fig. 8).

\subsubsection{Risk scenario C}

Risk scenario $\mathrm{C}$ considering all three risk-influencing factors of the Grosstal West avalanche showed a similar development as scenario B, but the increase between 1970 and 1980 was slightly lower due to the construction of the supporting structures (Figs. 7a and 8). For risk scenario C, 3.3\% of the total building values (risk scenario A) were calculated as possible loss in the year 2000 (Fig. 7a) because of the high number of buildings exposed to low pressures in this run-out zone. Taking into account the changes resulting from the construction of mitigation measures, the increasing values at risk and the varying vulnerabilities, the risk (scenario C) of the Grosstal West avalanche has doubled between 1950 and 2000 (Fig. 8).

The possible risk of loss for scenario $\mathrm{C}$ for the Grosstal East avalanche more than doubled already between 1950 and 1980 (Fig. 8). After the construction of a catching dam and the introduction of the hazard zone map in 1986, the values at risk in scenario $\mathrm{C}$ were reduced to $70 \%$ of the risk in 1980 (Fig. 7b). In general, this catching dam leads to a decline of risk, as illustrated by the proportion of the values resulting from risk scenario $\mathrm{C}$ to the total building values (risk scenario A). This proportion decreased from 5.5\% in 1950 to $1.9 \%$ in 2000 (Fig. 7b). The decline of risk in scenario C was followed by a slight increase until 2000 and resulted in an increase by a factor of 1.8 compared to the risk in 1950 (Fig. 8).

Risk scenario $\mathrm{C}$ regarding all three risk-influencing factors of the Gidisrinner avalanche showed a similar trend as scenario B until 1980 (Fig. 8). At this time, the possible loss in risk scenario $\mathrm{C}$ was calculated to exceed a quarter of the total building values (risk scenario A) (Fig. 7c). Due to the construction of supporting structures and the decrease of the vulnerability, this proportion was reduced to $1 \%$ until 2000 (Fig. 7c). Thus, the risk (scenario C) in 2000 was below the values of 1950 (by a factor of 0.9, Fig. 8), although, an increase of the total building values was detectable.

\section{Conclusions}

In comparison between 1950 and 2000, the development of risk of the three studied avalanche tracks differs considerably. The risk (scenario C) related to the Grosstal West and East avalanche doubled and nearly doubled, respectively. In contrast, the risk associated with the Gidisrinner avalanche in 2000 was just beneath the risk of the year 1950. In the following section, those different developments are analysed with respect to the factors influencing the risk.

The changes of the process behaviour resulting from the implementation of the supporting structures in the release area entailed different effects on the extent of the run-out zone as well as on the occurring avalanche pressures. Both Grosstal avalanches show only a marginal change of the 
extent of the run-out zone, and the associated pressures decreased only slightly. Unlike the minor decline of the risk related to the Grosstal West avalanche (= risk scenario C), the risk of the Grosstal East avalanche has decreased significantly after the construction of supporting structures. This difference is caused by the location of the exposed buildings. The area between the run-out zones of the Grosstal West avalanche regarding both the maximum and minimum scenario is nearly undeveloped. Therefore, the number of exposed objects was only reduced by a few buildings (Fig. 5). In the year 2000, more buildings are located in the fringe area of the Grosstal East run-out zone regarding the maximum scenario, which are not anymore exposed to the avalanche after the construction of the catching dam. The construction of supporting structures in the release area of the Gidisrinner avalanche effected a considerable reduction of the run-out zone as well as of the occurring pressures on the exposed buildings (Table 4). Thus, the risk decreased significantly after 1989 (Figs. 7c and 8). Considering the development of the process behaviour, it has to be concluded that not only smaller run-out zones and declining impact pressures cause a risk reduction. Furthermore, this reduction is highly influenced by the location, the distribution and the value of the exposed buildings in the area between the maximum scenario (without supporting structures) and the minimum scenario (considering supporting structures).

The development of the value at risk shows an increase of a factor of five between 1950 and 2000 for all three avalanche tracks. However, the trend during this period is slightly different between the Grosstal avalanches and the Gidisrinner avalanche (see Fig. 8). Nevertheless, a comparison of the total building values in the run-out zones of the three avalanches reveals remarkable differences. This discrepancy results from different numbers of exposed buildings and varying average values of the buildings due to changing building sizes and functions. There is no doubt that the increase of risk is a consequence of the rising total values of buildings, if it is assumed that changes in the avalanche activity are solely based on the implementation of mitigation measures. However, the trends of the total building values and the risk (regarding scenario B as well as C) are not directly correlated as shown especially for the Gidisrinner avalanche (see Fig. 8). An important aspect is the location of the buildings in the run-out zones. An increase of the building value in an area of high impact pressure (e.g. Gidisrinner avalanche) results in a higher risk than the same increase in the fringe area of the run-out zone with lower pressure (e.g. Grosstal avalanches).

The vulnerability of buildings to avalanche impacts declined for all three avalanche tracks between 1950 and 2000 . Changes in the type of building construction after 1960 (from building category 2 to 3 ) led to a decline of the susceptibility of the buildings. This was shown in the different development of possible losses in risk scenario B and the total building values (risk scenario A) of the Grosstal avalanches (see
Fig. 8). In areas with high avalanche pressure, the high susceptibility of the buildings - especially in the building categories 1 to 3 - results in high possible losses in risk scenario B (e.g. Gidisrinner avalanche). The construction requirements introduced in 1986 have only become operative in the legally defined hazard zones. Therefore, in the simulated run-out zones with a low proportion of buildings inside the hazard zones to buildings outside of the hazard zones, this regulation for decreasing the vulnerability of buildings shows no or only a slight decline of the possible loss in risk scenario B (see Grosstal avalanches in Figs. 7 and 8). In contrast, the regulation is considerably more effective in areas where high impact pressures occur and many buildings are already located in the hazard zones (e.g. Gidisrinner avalanche). Following the concept of Wilhelm (1997), the susceptibility of each building category cannot be reduced below a damage level with a possible loss of $3 \%$ of the total building value if an avalanche pressure above $2 \mathrm{kPa}$ occurs (see Fig. 2 and Sect. 2.3). This damage level is already reached regarding the proportion of the possible loss of risk scenario B to the total building values of the Grosstal East avalanche. The values of the Grosstal West avalanche are just above this level. Therefore, the risk can only be reduced with the help of constructive mitigation measures that decrease the impact pressures.

In this study, the temporal change of the risk related to three avalanche tracks in the community of Galtür has been investigated for the period from 1950 to 2000. The influences of each factor (process, value at risk, vulnerability) to the resulting risk was analysed and the connections between these factors were discussed. No general trend could be determined for the calculated risk. Similar results were obtained for both Grosstal avalanches comparing the years 1950 and 2000 , but they are caused by different aspects and influences. These aspects were the spatial distribution of the exposed objects, the values at risk, the occurring impact pressures and the related vulnerability of the objects, the effectiveness of the mitigation measures regarding both the extent of the runout zone and the reduction of the pressure as well as legal regulations. Small changes of one of these aspects can cause considerable differences in the resulting risk. These findings are consistent with recent studies in the Swiss Alps (Fuchs et al., 2004). Therefore, the assumption of different authors (Ammann, 2001; White et al., 2001; Barbolini et al., 2002) that high damage in the 1990s is mainly due to increasing values at risk cannot be confirmed by abstracting the results of this study to a general statement. These losses are a result of increasing complexity caused by changes of the geosystem and the social system and the connectivity between these systems.

The complexity of risk causes a high sensitivity of the calculated results to the risk-influencing factors. To determine these factors, a number of subsequent steps has to be conducted, each of them including several inherent uncertainties. A sensitivity and uncertainty analysis for this study 
is the subject of ongoing research. Regarding the probability of occurrence of the process, uncertainties resulting from avalanche simulations have to be taken into consideration. In addition to some basic limitations that occur when using simulation models, the major uncertainties result from the use of the input parameters, such as release depth and release extent. The values at risk are very sensitive to the building volume, and thus to the construction plans. Regarding the changing functions of the buildings, detailed research in archives has to be carried out to obtain the best suitable range of reinstatement costs (Keiler et al., 2004). Furthermore, future research has to be conducted regarding the vulnerability of buildings to avalanche impact pressure, since the method outlined in Wilhelm (1997) could only serve as a rough estimation.

Nevertheless, the multi-temporal approach applied in this study yields a better understanding of today's risk in alpine settlements by identifying the main changes and the underlying processes. Furthermore, this knowledge can be implemented in strategies for a sustainable development in Alpine settlements, which is promoted in the Agenda 21 (United Nations, 1992).

Acknowledgements. The authors would like to express their sincere thanks to the colleagues at the University of Innsbruck, Department of Geography, for valuable discussion and support; as well as the public authorities in the municipality of Galtuir for providing data. Furthermore, the authors kindly acknowledge D. Issler and another referee for their insightful comments on an earlier version of the paper. Part of the research for this study was carried out by means of grants donated by Munich Re Reinsurance Company.

Edited by: T. Glade

Reviewed by: D. Issler and two other referees

\section{References}

Ammann, W.: Integrales Risikomanagement - der gemeinsame Weg in die Zukunft, Bündnerwald, 5, 14-17, 2001.

Bader, S. and Kunz, P. (Eds.): Klimarisiken - Herausforderungen für die Schweiz, vdf Hochschulverlag, Zürich, 1998.

Barbolini, M., Natale, L., and Savi, F.: Effects on release conditions uncertainty on avalanche hazard mapping, Nat. Hazards, 25, 225-244, 2002.

Barbolini, M., Cappabianca, F., and Sailer, R.: Empirical estimate of vulnerability relations for use in snow avalanche risk assessment, edited by: Brebbia, C., Risk Analysis IV, WIT Press, Southampton, 533-542, 2004.

Bätzing, W.: Der sozio-ökonomische Strukturwandel des Alpenraums im 20. Jahrhundert, Bern, Geographica Bernensia, P26, 1993.

Bell, R. and Glade, T.: Quantitative risk analysis for landslides examples from Bíldudalur, NW Iceland, Nat. Hazards Earth Syst. Sci., 4, 117-131, 2004, http://www.nat-hazards-earth-syst-sci.net/4/117/2004/.
Bergthaler, J.: Grundsätze zur Erarbeitung von Gefahrenzonenplänen in Wildbächen der Nördlichen Kalkalpen und der Grauwackenzone, Österr. Wasserwirtschaft, 27, 160-168, 1975.

Bründl, M. and Hegg, C.: Die Naturereignisse der letzten Jahre im Überblick, edited by: WSL (Swiss Federal Institute for Forest, Snow and Landscape Research), Forum für Wissen 2001, Birmensdorf, http://www.wsl.ch/slf/pdf/forum2001-bruendl-hegg. pdf, access 21 July 2005, 2001.

BWG (Swiss Federal Office for Water and Geology): Priorisierungsverfahren für Hochwasserschutzprojekte - Abschätzung des Schadenpotentials, http://www.bwg.admin.ch/ service/download/d/index.htm $\backslash \#$ schapo, access 25 May 2005, 2005.

Cutter, S.: Vulnerability to environmental hazards, Progr. Human Geogr., 20, 529-539, 1996.

Frutiger, H.: Rechtliche Aspekte der Nutzungsbeschränkung des Grundeigentums wegen Lawinengefährdung, Proc. Internationales Sympos. Interpraevent - Bad Ischl, Austria, 8-12 September 1980, 1, 33-48, 1980.

Fuchs, S. and Bründl, M.: Damage potential and losses resulting from snow avalanches in settlements in the Canton of Grisons, Switzerland, Nat. Hazards, 34, 53-69, 2005.

Fuchs, S. and Keiler, M.: Natural hazard risk depending on the variability of damage potential, edited by: Brebbia, C. and Popov, V., Risk Analysis V, WIT-Press, Southampton, 13-22, 2006.

Fuchs, S., Bründl, M., and Stötter, J.: Development of avalanche risk between 1950 and 2000 in the municipality of Davos, Switzerland, Nat. Hazards Earth Syst. Sci., 4, 263-275, 2004, http://www.nat-hazards-earth-syst-sci.net/4/263/2004/.

Fuchs, S., Keiler, M., Zischg, A., and Bründl, M.: The longterm development of avalanche risk in settlements considering the temporal variability of damage potential. Nat. Hazards Earth Syst. Sci., 5, 893-901, 2005, http://www.nat-hazards-earth-syst-sci.net/5/893/2005/.

Gächter, M. and Bart, R.: Risikoanalyse und Kostenwirksamkeit bei der Massnahmenplanung - Beispiel Diesbach, Schweiz. Z. f. Forstwesen, 153, 268-273, 2002.

Gemeinde Galtür: Statistik Galtür, http://www.galtuer.gv.at, access 27 June 2006, 2006.

Glade, T.: Vulnerability assessment in landslide risk analysis, Die Erde, 134, 123-146, 2003.

Heumader, J.: Die Katastrophenlawinen von Galtür und Valzur am 23. und 24.2.1999 im Paznauntal/Tirol, Proc. Internationales Sympos. Interpraevent - Villach, Austria, 26-30 June 2000, 2, 397-410, 2000.

Hollenstein, K., Bieri, O., and Stückelberger, J.: Modellierung der Vulnerability von Schadenobjekten gegenüber Naturgefahrenprozessen, Schlussbericht, ETH Zürich, Dept. Forstliches Ingenieurwesen, http://e-collection.ethbib.ethz.ch/ show?type=bericht\&nr=173, access 8 April 2005, 2002.

Hufschmidt, G., Crozier, M., and Glade, T.: Evolution of natural risk: research framework and perspectives, Nat. Hazards Earth Syst. Sci., 5, 375-387, 2005, http://www.nat-hazards-earth-syst-sci.net/5/375/2005/.

IUGS (International Union of Geological Sciences): Quantitative risk assessment for slopes and landslides - the state of the art, edited by Cruden, D. and Fell, R.: Landslide Risk Assessment., Proc. of the International Workshop on Landslide Risk Assessment - Honolulu, Hawaii, USA, 19-21 February 1997, Balkema, 
Rotterdam, 3-12, 1997.

Jónasson, K., Sigurdsson, S., and Arnalds, T.: Estimation of avalanche risk, Icelandic Meteorological Office, Reykjavík, Iceland, VÍ-R99001-ÚR01, 1999.

Keiler, M.: Development of the damage potential resulting from avalanche risk in the period 1950-2000, case study Galtür, Nat. Hazards Earth Syst. Sci., 4, 249-256, 2004, http://www.nat-hazards-earth-syst-sci.net/4/249/2004/.

Keiler, M., Meiß1, G., and Stötter, J.: Determination of the damage potential: a contribution to the determination of avalanche risk, edited by: Brebbia, C., Risk Analysis IV, WIT Press, Southampton, 187-196, 2004.

Keiler, M., Zischg, A., Fuchs, S., Hama, M., and Stötter, J.: Avalanche related damage potential - changes of persons and mobile values since the mid-twentieth century, case study Galtür, Nat. Hazards Earth Syst. Sci., 5, 49-58, 2005, http://www.nat-hazards-earth-syst-sci.net/5/49/2005/.

Keylock, C. and Barbolini, M.: Snow avalanche impact pressure vulnerability relations for use in risk assessment, Can. Geotech. J., 38, 227-238, 2001.

Keylock, C., McClung, D., and Magnússon, M.: Avalanche risk mapping by simulation, J. Glaciol. 45, 303-314, 1999.

Kleist, L., Thieken, A., Köhler, P., Müller, M., Seifert, I., and Werner, U.: Estimation of building values as a basis for a comparative risk assessment, edited by: Mahlzahn, D. and Plapp, T., Disasters and society, Logos Verlag, Berlin, 115-122, 2004.

Laternser, M.: Snow and avalanche climatology in Switzerland, PhD-thesis, Diss. ETH No. 14493, ETH Zürich, 2002.

Sailer, R., Rammer, L., and Sampl, P.: Recalculation of an artificially released avalanche with SAMOS and validation with measurements from a pulsed Doppler radar, Nat. Hazards Earth Syst. Sci., 2, 211-216, 2002,

http://www.nat-hazards-earth-syst-sci.net/2/211/2002/.
Sampl, P. and Zwinger, T.: Avalanche simulation with SAMOS, Ann. Glaciol., 38, 393-396, 2004.

Schneebeli, M., Laternser, M., Föhn, P., and Ammann, W. : Wechselwirkungen zwischen Klima, Lawinen und technischen Massnahmen, vdf Hochschulverlag, Zürich, 1998.

SLF (Ed.): Der Lawinenwinter 1999, SLF (Eidgenössisches Institut für Schnee- und Lawinenforschung), Davos, 2000.

United Nations: Agenda 21, http://www.un.org/esa/sustdev/ documents/agenda21/index.htm, access 13 July 2005, 1992.

Voellmy, A.: Ueber die Zerstörungskraft von Lawinen, Schweiz, Bauzeitung, 73, 159-165, 1955.

Volk, G. and Kleemayr, K.: Lawinensimulationsmodell ELBA, Wildbach- und Lawinenverbau, 138, 23-32, 1999.

Weiss, G.: The political practice of natural hazards control in Austria and the question of climate change, edited by: Steininger, M. and Weck-Hannemann, H., Global environmental change in alpine regions, Edward Elgar, Cheltenham, 131-149, 2002.

White, G., Burton, R., and Kates, I.: Knowing better and loosing even more: the use of knowledge in hazards management, Environ. Hazards 3, 81-92, 2001.

Wilhelm, C.: Wirtschaftlichkeit im Lawinenschutz, Mtt. Eidgenössisches Institut für Schnee- und Lawinenforschung, 54, Davos, 1997.

Wisner, B., Blaikie, P., Cannon, T., and Davis, I. (Eds.): At risk, Routledge, London, 2003.

Zischg, A., Fuchs, S., Keiler, M., and Stötter, J.: Temporal variability of damage potential on roads as a conceptual contribution towards a short-term avalanche risk simulation, Nat. Hazards Earth Syst. Sci., 5, 235-242, 2005,

http://www.nat-hazards-earth-syst-sci.net/5/235/2005/. 